Turk Med Stud J 2022;9(1):41-4

CASE REPORT

DOI: 10.4274/tmsj.galenos.2022.09.01.09

\title{
MITRAL VALVE INFECTIVE ENDOCARDITIS IN AN INTRAVENOUS DRUG ABUSER
}

\author{
Buket Şen ${ }^{1}$ (D), Utku Yartaşı ${ }^{1}$ (D), Servet Altay ${ }^{2}$ (i) \\ ${ }^{1}$ Trakya University School of Medicine, Edirne, TURKEY \\ ${ }^{2}$ Trakya University School of Medicine, Department of Cardiology, Edirne, TURKEY
}

\section{ABSTRACT}

Infective endocarditis is a disease characterized by endocardial surface infection of the heart with high mortality and morbidity. The infection mostly involves heart valves, defects, or permanent heart devices. The aim of this case is to present a young patient with mitral valve involvement and infective endocarditis who is an intravenous drug abuser. A 26-year-old male patient was admitted to the Trakya University School of Medicine Hospital Emergency Service with complaints of fever and shortness of breath lasting for 10 days. The patient had no medical history other than active smoking and intravenous drug use. On physical examination of the patient, an apical 2/6 systolic murmur was detected. Transthoracic echocardiography performed with the suspicion of infective endocarditis revealed a large mobile mass in the mitral valve. Transesophageal echocardiography was performed to confirm the diagnosis. This revealed an open foramen ovale pattern and moderate mitral regurgitation. Increased inflammatory parameters and positive blood cultures for Staphylococcus aureus were detected in the laboratory. The patient was operated on for mitral valve replacement with a definitive diagnosis of infective endocarditis. Infective endocarditis is a disease that can be difficult to diagnose because of its clinical presentations similar to other diseases. Therefore, infective endocarditis should be considered in the etiology of fever, unexplained worsening of general condition, and a newly developed heart murmur, especially in people using intravenous drugs.

Keywords: Infective endocarditis, intravenous substance abuse, mitral valve

\section{INTRODUCTION}

Infective endocarditis (IE) is known as infection of natural or prosthetic heart valves, endocardium, or intracardiac devices caused by bacterial, viral, or fungal pathogens $(1,2)$. Up to 10 out of every 100,000 people are affected by IE each year (3). Despite advances in its management, IE has still been considered a disease with a high risk of morbidity and mortality, a $15-20 \%$ in-hospital mortality risk, and a one-year mortality rate of up to $40 \%$ (4). In recent years, changes have been observed in the epidemiology of IE due to the aging of the population, the increase in the number of people using intravenous drugs, and the use of artificial heart devices and heart valves (3).

The type of affected valve and the duration of the infection period are used to classify IE (4). The distinction between natural and prosthetic valve endocarditis is important for clinical management. The period of the infection is classified as acute (few days- 6 weeks), subacute ( 6 weeks- 3 months), and chronic endocarditis (more than 3 months) according to the duration of infection and the time interval when signs and symptoms occur (5).

In this case report, we present an unusually located IE without any predisposing heart disease in a young intravenous (IV) drug abuser patient.

\section{CASE REPORT}

A 26-year-old male patient with a history of active smoking and IV drug use, was admitted to the Trakya University Hospital emergency department with complaints of fever and shortness of breath lasting for 10 days. On physical

Address for Correspondence: Buket Şen, Trakya University School of Medicine, Edirne, TURKEY

e-mail: buketsen99@hotmail.com

ORCID iDs of the authors: BSุ: 0000-0001-7708-8280; UY: 0000-0002-2411-8949; SA: 0000-0001-7112-3970.

Received: 05.01.2022 Accepted: 19.01.2022

Cite this article as: Şen B, Yartaşı U, Altay S. Mitral valve infective endocarditis in an intravenous drug abuser.

Turk Med Stud J 2022;9(1):41-4.

Copyright@Author(s) - Available online at https://www.turkmedstudj.com/ 
examination, body temperature was $39.1^{\circ} \mathrm{C}$, blood pressure was 110/60 mmHg, sinus tachycardia at a rate of 104 beats/ min, and an apical 2/6 systolic murmur was found. Due to suspicion of IE, a transthoracic echocardiogram was performed, and it revealed a $17 \times 22 \mathrm{~mm}$ mobile mass on the mitral valve, which was compatible with vegetation (Figure 1, 2). Transesophageal echocardiography (TEE) was performed to confirm the diagnosis of IE. Patent foramen ovale (PFO) was observed in the interatrial septum on TEE. Vegetation appearance and moderate mitral regurgitation were observed on the mitral valve. The patient was hospitalized with a preliminary diagnosis of IE. Laboratory results showed leukocytosis (white blood cells $17 \times 10^{9} / \mathrm{L}$ ), elevated C-reactive protein (56 $\mathrm{mg} / \mathrm{L})$, and increased erythrocyte sedimentation rate $(95 \mathrm{~mm} / \mathrm{h})$. Staphylococcus aureus was detected in two separate blood cultures. The patient was diagnosed with definitive IE according to the modified Duke criteria (1), two major criteria were met with positive blood culture and vegetation. Mitral valve replacement was performed with

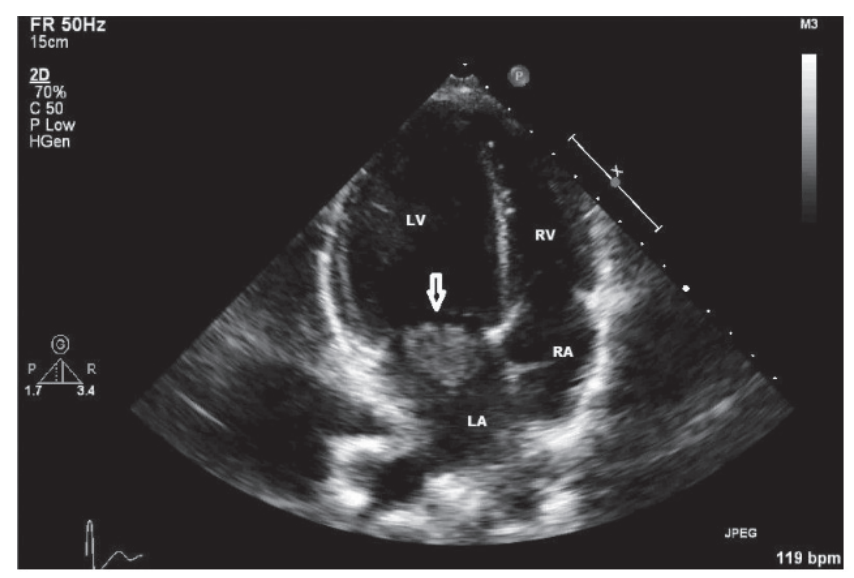

Figure 1: On the mitral valve, the mass is compatible with the vegetation (arrow).

RV: Right ventricle, RA: Right atrium, LA: Left atrium, LV: Left ventricle

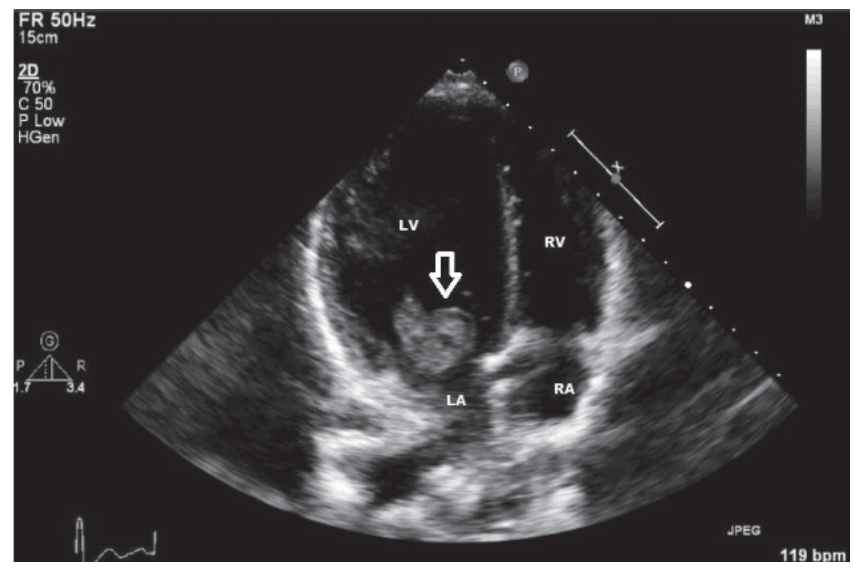

Figure 2: The entrance of the mobile vegetation into the left ventricle is observed (arrow).

RV: Right ventricle, RA: Right atrium, LA: Left atrium, LV: Left ventricle the agreement of the cardiac medical council. 1,000 $\mathrm{mg}$ IV vancomycin treatment was administered 3x1 (3,000 mg/ day). The patient was discharged on the $27^{\text {th }}$ day. Routine check-ups were recommended to the patient after discharge.

\section{DISCUSSION}

The diagnosis of IE is made using modified Duke criteria (1). For the diagnosis of IE, the patient must fulfill either: 2 major, 1 major plus 3 minor, or 5 minor criteria. Two major criteria, one is positive blood culture consistent with IE, and the other is the demonstration of findings such as vegetation, intracardiac abscess, or valve regurgitation on echocardiography. Minor criteria are the presence of predisposing factors such as heart disease or IV drug use, body temperature $>38{ }^{\circ} \mathrm{C}$, vascular events (intracranial hemorrhage, Janeway lesions), immunological events (Osler nodules, Roth spots, rheumatoid factor positivity), and microbiological evidence such as blood culture positivity that does not meet major criteria. Since there were 2 major criteria seen in this patient, the diagnosis was definitive IE $(1,4)$. According to most studies, S. aureus is the most common cause of IE, accounting for $26.6 \%$ of all cases (3). Viridans streptococci (18.7\%), other streptococci $(17.5 \%)$, and enterococci $(17.5 \%)$ are the next most common causes of IE (10.5\%) (3). These pathogens cause almost $90 \%$ of all cases of endocarditis (3). S. aureus is also the most prevalent pathogen, particularly in IV drug-associated IE cases (6). There are predisposing factors that contribute to the onset of IE, such as previous IE history, dental infection, cardiac pacemaker, prosthetic heart valve, or congenital structural heart disease (7). Moreover, IV-applied drugs, which cause bacterial contamination of the heart through the blood, also become the leading risk factor of IE (7). In this case, our patient does not have any structural predisposing factors in the mitral valve for the onset of IE. Therefore, IV drug usage appears to be the most important predisposing factor. IV drug-associated IE turns out to be a predisposing factor in $10 \%$ of all IE cases in developed countries (8). In cases of IE related to using IV drugs, the tricuspid valve is affected the most often; however, the mitral or aortic valves can also be affected, which in our patient, we determined mitral valve vegetation (9).

Interestingly, the tricuspid valve was free of vegetation. We explained this rare condition with the existence of a PFO that we observed in TEE; however, this situation can be explained by hematogenous spread, although it is rare. This case illustrates the need for considering left-sided valve endocarditis in IV drug abusers with septicemia, even if the tricuspid valve shows no evidence of vegetation (10).

The treatment of IE generally consists of antimicrobial therapy and is arranged for the pathogen obtained from 
the blood culture (11). The duration of treatment may vary depending on the type of valve involved and the isolated pathogen; however, in IV drug-related IE, antibiotic treatment is usually 4-6 weeks long (12). As in our case, $S$. aureus is the most observed pathogen in blood cultures. According to the latest treatment protocols in Turkey, cefazolin is the first-line treatment for methicillin-sensitive S. aureus IE (13). Daptomycin should be preferred in patients with anaphylactic hypersensitivity reactions to $\beta$-lactams. In prosthetic valve $\mathrm{IE}$, a combination of cefazolin, gentamicin, and rifampicin is suggested (13). A combination of vancomycin and cefazolin can be prescribed to patients with methicillin-resistant $S$. aureus IE, particularly in cases of persistent bacteremia ( $>3-7$ days) (13).

Although patients with IE require surgical treatment, the timing of surgical intervention varies according to the surgical indication. In some cases, surgical intervention is performed urgently 24 hours after admission, while in some cases, elective surgery can be performed within 7-14 days (14). Depending on the affected region, the indications for surgical intervention and the type of surgery to be performed are different $(13,15)$. In this case, the mitral valve on the left side of the heart was affected. The most common indications for surgery in patients with IE are heart failure, prevention of embolism, and uncontrollable/invasive infections caused by resistant microorganisms $(13,16)$. Our patient underwent surgery due to the observation of significantly larger than $10 \mathrm{~mm}$ vegetation on the mitral valve with moderate mitral regurgitation.

Antimicrobial prophylaxis is recommended before hemorrhagic intraoral procedures in patients with predisposing cardiac conditions that may result in IE (previous IE history, presence of artificial heart valve, heart transplant recipients with valvulopathy, and cyanotic congenital heart diseases) (17). For prophylaxis, 30-60 minutes before the dental procedure, amoxicillin/ampicillin can be administered to patients who are not allergic to $\beta$-lactams intravenously or orally $2 \mathrm{gr}$ in adults, $50 \mathrm{mg} / \mathrm{kg}$ in children (18). If the patient is allergic to $\beta$-lactams, clindamycin can be given $600 \mathrm{mg}$ in adults and $20 \mathrm{mg} / \mathrm{kg}$ in children (18).

It is critical to determine the prognosis of a patient diagnosed with IE in terms of both treatment management and estimation of mortality risk. The patient should be evaluated at the time of diagnosis, in the first week following antibiotic therapy, and before discharge from the hospital. According to the simplified risk score used in the evaluation, plans such as aggressive treatment, early surgery, and transfer to the intensive care unit are considered (13). Poor prognosis markers can be classified under three headings as patient-related variables (aging, prosthetic heart valve, diabetes mellitus), complications of IE (heart failure, renal failure, stroke, sepsis), and etiological pathogenic microorganisms (S. aureus, fungus) (19). The prognosis of artificial valve endocarditis is worse than natural valve endocarditis because it is more difficult to diagnose and treat (13). In addition, clinical studies show that left-sided IE has a worse prognosis than right-sided IE (15).

In the case we presented, surgery was decided because IE caused mitral valve regurgitation and had large, mobile vegetation. In conclusion, IE should be considered in the etiology of fever, unexplained worsening of general condition, and newly developed heart murmur in people using IV drugs.

\section{Ethics Committee Approval: N/A}

Informed Consent: Informed verbal consent was obtained from the next of kin.

Conflict of Interest: The authors declared no conflict of interest.

Author Contributions: Concept: B.Ş., U.Y., S.A., Design: B.Ş., U.Y., S.A., Supervision: B.Ş., U.Y., S.A., Resources: B.Ş., U.Y., S.A., Materials: B.Ş., U.Y., S.A., Data Collection and/or Processing: B.Ş., U.Y., S.A., Analysis and/or Interpretation: B.Ş., U.Y., S.A., Literature Search: B.Ş., U.Y., S.A., Writing Manuscript: B.Ş., U.Y., S.A., Critical Review: B.Ş., U.Y., S.A.

Financial Disclosure: The authors declared that this study received no financial support.

\section{REFERENCES}

1. National Organization for Rare Disorders. Infective Endocarditis (cited 2020). Available from: URL: https://rarediseases.org/rare-diseases/ endocarditis-infective/. [Crossref]

2. Muço E, Harxhi A, Hasa A et al. Infective endocarditis related to intravenous drug user: report of four cases. Open Infect Dis J 2018;10: 1-8. [Crossref]

3. Rajani R, Klein JL. Infective endocarditis: A contemporary update. Clin Med (Lond) 2020;20:31-5. [Crossref]

4. Otto CM, Nishimura RA, Bonow RO et al. 2020 ACC/AHA Guideline for the Management of Patients With Valvular Heart Disease: Executive Summary: A Report of the American College of Cardiology/American Heart Association Joint Committee on Clinical Practice Guidelines. J Am Coll Cardiol 2021;77:450-500. [Crossref]

5. Hubers SA, DeSimone DC, Gersh BJ et al. Infective Endocarditis: A Contemporary Review. Mayo Clin Proc 2020;95:982-97. [Crossref]

6. Goyal A, Mohan B, Kumar P et al. Clinical characteristics and outcome of infective endocarditis among intravenous drug abusers in India. Indian Heart J 2020;72:547-51. [Crossref]

7. Holland TL, Baddour LM, Bayer AS et al. Infective endocarditis. Nat Rev Dis Primers 2016;2:16059. [Crossref]

8. Şimşek-Yavuz S, Şensoy A, Kaşıkçıŏlu $\mathrm{H}$ et al. Infective endocarditis in Turkey: aetiology, clinical features, and analysis of risk factors for mortality in 325 cases. Int J Infect Dis 2015;30:106-14. [Crossref]

9. Meel R. Right-sided infective endocarditis secondary to intravenous drug abuse. In: Magnusson P, Razmi R, editors. Infective Endocarditis. London: IntechOpen; 2019. doi: 10.5772/intechopen.84319. [Crossref] 
10. Seghatol F, Grinberg I. Left-sided endocarditis in intravenous drug users: a case report and review of the literature. Echocardiography 2002;19:509-11. [Crossref]

11. Martí-Carvajal AJ, Dayer M, Conterno LO et al. A comparison of different antibiotic regimens for the treatment of infective endocarditis. Cochrane Database Syst Rev 2016;4:CD009880.[Crossref]

12. Ji Y, Kujtan L, Kershner D. Acute endocarditis in intravenous drug users: a case report and literature review. J Community Hosp Intern Med Perspect 2012;2. [Crossref]

13. Şimşek-Yavuz $S, A k a r$ AR, Aydoğdu $S$ et al. İnfektif endokarditin tanısı, tedavisi ve önlenmesi: Ulusal uzlaşı raporu. Klimik Derg 2019;32 (Suppl 1):2-116. [Crossref]

14. Morjan M, Van Hemelrijk M, Maisano F et al. Contemporary surgery in infective endocarditis. EJCM 2019;7:166-71. [Crossref]

15. Moldovan $H$, Adrian $M$, Victor $C$ et al. Infective endocarditis in intravenous drug users: surgical treatment. In: Magnusson P, Razmi R, editors. Infective Endocarditis. London: IntechOpen; 2019. doi: 10.5772/ intechopen.84708. [Crossref]

16. Prendergast BD, Tornos P. Surgery for infective endocarditis: who and when? Circulation 2010;121:1141-52. [Crossref]

17. Allen U. Infective endocarditis: Updated guidelines. Can J Infect Dis Med Microbiol 2010;21:74-7. [Crossref]

18. Habib G, Lancellotti P, Antunes MJ et al. 2015 ESC Guidelines for the management of infective endocarditis: The Task Force for the Management of Infective Endocarditis of the European Society of Cardiology (ESC). Endorsed by: European Association for Cardio-Thoracic Surgery (EACTS), the European Association of Nuclear Medicine (EANM). Eur Heart J 2015;36:3075-128. [Crossref]

19. Gálvez-Acebal J, Rodríguez-Baño J, Martínez-Marcos FJ et al. Prognostic factors in left-sided endocarditis: results from the Andalusian multicenter cohort. BMC Infect Dis 2010;10:17. [Crossref] 